\title{
Towards Profitable Growth in E-Grocery Retailing - the Role of Store and Household Density
}

\author{
Joydeep Paul, Niels Agatz \\ Rotterdam School of Management, Erasmus University nagatz@rsm.nl \\ Jan Fransoo \\ Tilburg School of Economics and Management Jan.Fransoo@tilburguniversity.edu
}

\begin{abstract}
Despite the continued growth of e-grocery sales, few companies actually make any profits in this retail segment. Increasing market shares and associated drop densities may render profitable operations possible, but higher delivery fees seem essential to achieving profitability. Yet such higher fees may put e-groceries at a disadvantage as compared with the traditional store channel, which remains highly competitive. This study models customer choice between the e-grocery channel and the store channel as well as the effects of that choice on those channels' operational costs and market shares. We identify conditions under which e-grocery retail can be profitable, and we estimate our model's parameters using secondary industry data. Our results indicate that e-grocery is profitable when household density is high and store density is low. When customer valuation of the e-grocery channel increases substantially, the result may be cannibalization of the store channel's sales to the extent that stores encounter losses. Thus there are three paths to e-grocery profitability:(i) a substantial increase in the relative consumer valuation of the online channel; (ii) a focus on areas with high household density and low store density; (iii) a long-term subsidy of the online channel until stores begin to close.
\end{abstract}

Key words: E-Grocery; Customer-choice model; Channel cannibalization;

\section{Introduction}

Online grocery sales have seen spectacular growth rates world wide, especially during the Covid-19 pandemic (ResearchAndMarkets.com 2020). However, online sales still account for only 5\%-10\% of total grocery sales in most markets. One of the main reasons that e-grocery sales have not developed as rapidly as other categories, such as electronics and books, is the operational challenges involved. Grocery products are bulky and fragile; they also include fresh food with expiration dates and different temperature requirements. A typical grocery order consists of 30-60 different stockkeeping units (Seow et al. 2003) that need to be "picked" individually. Moreover, the customers in home delivery setups must be at home in order to receive the goods - which necessitates the use of time windows to coordinate receipt of the groceries (Agatz et al. 2011). 
E-grocery operations are characterized by high costs per transaction. The two primary cost drivers are order picking and last-mile delivery operations. In picking, the cost per customer order depends mostly on the level of automation (Hübner et al. 2016). In last-mile delivery, costs depend on the drop density (i.e., number of deliveries per fixed area) and the service time spent at the customer. A higher drop density is associated with lower travel times and less distance between customers. Because drop density is related to the number of customers that can be served together in space and time, it is linked also to lead times, time-window options, household density, and total number of customers that shop online. Service time depends on the size of the order and on the retailer's specific service offering. For instance, it generally takes more time to deliver "into the kitchen" than simply to the doorstep.

Since the delivery fee is a barrier to shopping online, grocers typically charge a low fee (or even offer free delivery) to attract more customers. Given the low profit margins of grocery products and the relatively small order sizes, the retailer's per-order fulfillment costs often exceed the associated revenue (Capgemini 2019). Thus e-grocery operations - whether conducted by pure players or multi-channel retailers - generally incur losses. For example, the UK-based e-grocery retailer Ocado reported a 2214 million loss in 2019 (Castia 2020).

There is ongoing debate over whether or not online grocery will ever be more than a niche market (Dannenberg et al. 2020). Several industry analysts expect e-grocery market shares to reach double digits in the next 5-10 years (Colliers International 2019, FMI et al. 2020), and hundreds of millions of dollars have been invested in e-grocery operations around the world (Ecommerce News Europe 2019, Begley et al. 2020, Park 2020). At the same time, others are more critical. The retail bank HSBC is "unconvinced of [the] long-term viability of home deliveries for grocery" (Edwards 2016). In a recent study of the German market, Dannenberg et al. (2020) conclude that "even the unprecedented growth in e-grocery during the [Covid-19] crisis does not indicate a fundamental long-term shift from stationary to online food retail."

What is often missing in this debate is a good understanding of the interaction between the store channel and the e-grocery channel. On the one hand, growth in the online market share is typically at the expense of the store channel. On the other hand, studies have shown that e-grocery sales increase disproportionately in areas with less store coverage (Chintagunta et al. 2012). Hence the growth of e-grocery shopping cannot be studied separately from developments in the store channel.

The two sales channels have different value propositions. The e-grocery channel provides customers with the convenience of home delivery, but it may also be perceived as costly and inflexible because it requires customers to plan ahead. In contrast, brick-and-mortar stores provide instant gratification and allow customers to touch and feel fresh items without having to wait or pay delivery fees (NPD 2018). The situation is in constant flux as both channels continuously look for ways to improve the shopping experience for customers. 
Our study focuses on how household and store densities affect the market shares of the e-grocery and store channels. For the online channel, higher household density is associated with higher drop densities and thus lower last-mile fulfillment costs - characteristics that allow for more competitive pricing of the online service to win market share. Yet we show that, contrary to conventional wisdom, higher household densities do not always lead to a more competitive e-grocery channel because store densities are then typically higher as well. Thus we observe competing effects, as high household densities correspond to lower fulfillment costs whereas high store densities limit the appeal of home online grocery. To analyze this intriguing relationship, we develop a stylized model of cross-channel choice behavior that captures the effects of household and store densities while incorporating the different cost structures of each channel. The model considers a grocery retailer that operates both a network of stores and an e-grocery home delivery service. Customers choose to shop for groceries through the e-grocery channel, at the store, or via an outside alternative. We calibrate the model using empirical data from an European context and then derive insights into how markets shares could evolve in different environments.

We find that e-grocery channel profits increase with household density but decrease with store density. Picking costs also play a significant role in the profitability of the e-grocery channel. When the retailer's two channels are jointly optimized, e-grocery is a profitable option only when picking costs are low. In addition, we document that increases in customer valuations of the e-grocery channel can significantly boost its profitability. An increase in online sales will come at the expense of sales in the store channel, which jeopardizes that channel's financial viability. One possible outcome is the eventual closing of stores.

Our results suggest three strategic paths to profits in e-grocery: service, niche, or subsidies. The service path requires a substantial increase in valuation of the online channel in comparison to the store channel; only such an increase can induce customers to pay higher delivery fees. The niche path requires that the online channel focus on areas with high household density and low store density. In these areas, the relative costs of the online channel are most competitive while valuations of the store channel are relatively low - given the costs of traveling to a store. Finally, the subsidy path relies on the deep pockets of investors and shareholders to subsidize the online channel until such time that stores face imminent closure. In that event, the store channel's relative valuation declines and so the online channel can charge higher delivery fees.

This study's principal contributions can be summarized as follows. First, we present a stylized model that allows one to study the "cannibalization" of sales between the e-grocery channel and the store channel. Thus we model customer choice behavior across sales channels as well as its effects on operational fulfillment costs. In this model, we bring together different aspects that have previously been studied only in isolation. Second, we provide fundamental new insights into the 
drivers of the e-grocery channel's profitability and market share. Finally, we calibrate our model based on real-world industry data and thereby illuminate expected developments in the market shares of the different channels in various environments.

The rest of our paper proceeds as follows. Section 2 reviews the related literature. In Section 3 , we formally describe the model. Section 4 presents some theoretical results, and Section 5 reports the results from our numerical experiments. We conclude in Section 6 with a summary of our key findings and suggestions for future research.

\section{Literature review}

This paper contributes to the literature on omni-channel grocery retailing. Our method builds on research addressing customer choice behavior and the literature on e-grocery operations.

So-called attraction demand models are commonly used to model consumer choice in marketing, economics, operations, and revenue management (Harsha et al. 2019). There is a large stream of literature that uses stylized attraction models to study the interaction between different sales channels. Bernstein et al. (2008) focus on the benefits, for a traditional brick-and-mortar retailer, of adding an e-grocery channel. They derive multinominal logit models and study industry equilibria for different market conditions. In a similar vein, these models have been used to study a variety of specific omni-channel retail settings, such as "showrooming" (Balakrishnan et al. 2014) and "buy online with pickup in store" (Gao et al. 2021). Most of the extant work considers channel choice and pricing based on simple linear cost models. In contrast, we focus on effects of the nonlinear fulfillment costs typical of e-grocery retailing. In particular, we model marginal fulfillment costs that - owing to economies of scale - decrease with the number of orders. Moreover, whereas most papers in this stream of work are devoted to developing theoretical frameworks, we collect empirical input data to provide real-world insight on potential market shares and the profitability of grocery operations.

The empirical research on channel choice in grocery retailing is limited. Previous studies on egrocery shopping compare online and offline purchase behavior in terms of brand loyalty (Danaher et al. 2003), shopping behavior (Andrews and Currim 2004, Breugelmans et al. 2007, Kull et al. 2007), and consumers' perceptions of shopping online for groceries (Ramus and Nielsen 2005). Chintagunta et al. (2012) empirically quantify different types of transaction costs in the online and offline grocery channels. Boyer and Hult (2005) show, in an e-grocery context, the importance of the retailer's website - and of product and service qualities - for encouraging repeat purchase intentions.

A number of papers discuss the advantages and disadvantages of different strategies for e-grocery and omni-channel fulfillment operations (Yrjo et al. 2001, de Koster 2002, Hays et al. 2005, Hübner 
et al. 2016). There is a growing body of research on the specific challenges of offering an effective and cost-efficient grocery delivery service, especially as regards last-mile operations. Several early studies focus on how customer density and the length of the delivery time window affect last-mile delivery costs (Lin and Mahmassani 2002, Boyer et al. 2009). Others have addressed optimizing the design of the time-window offering in order to facilitate efficient routing operations and customer service (Agatz et al. 2011, Yang et al. 2016) while discussing the related (dynamic) pricing decisions (Klein et al. 2019, Strauss et al. 2020, Vinsensius et al. 2020). In this paper, we apply continuous approximation (cf. Ansari et al. 2018) to estimate the expected last-mile distances for different drop densities. Such routing approximations are well suited for strategic analysis of the case where customer locations are not precisely known.

Order picking constitutes a large portion of the costs of online order fulfillment (Kämäräinen et al. 2001). It is well documented that warehouse-based picking is more efficient than store-based picking (Hübner et al. 2016). Although there is extensive research on warehouse operations and order picking for e-commerce (Boysen et al. 2019), much less attention has been given - in the literature on warehouse layout design and order-picking strategies - to the particular challenges of picking groceries (e.g., temperature zones, sensitive products). One notable exception is the recent work of Vazquez-Noguerol et al. (2021), who study how best to organize picking processes for the e-grocery channel in a regular store. Their empirical work highlights the need to account for different product and order characteristics when designing a process for picking.

\section{Model}

We consider a grocery market of area $A$ in which $N^{h}$ households and $N^{s}$ grocery stores are uniformly distributed. Let $\delta^{h}=N^{h} / A$ be the household density. Consider an omni-channel grocery retailer that serves the market through its $N_{s}^{s}$ stores and also through its e-grocery channel with home delivery service. Households buy fresh groceries at the stores or via the e-grocery channel; they also have the option of obtaining their groceries from an outside option. Since the share of the store channel in the grocery market is large, we represent the outside option by the stores not belonging to our retailer. We assume that weekly spending is uniform. The gross margins for the e-grocery and store channels are denoted by $m_{e}$ and $m_{s}$, respectively.

\subsection{Customer choice model}

To model household choice for grocery shopping, we use a general "attraction demand" model (Huang et al. 2013). Customers choose between different channels so as to maximize their utility. Here, each channel has a specific utility that is associated with the attractiveness of the shopping 
experience in that channel. Let $u_{e}$ denote the utility of the e-grocery channel, $u_{s}$ of the store channel, and $u_{o}$ of the outside option.

A customer incurs also certain disutilities when shopping online or in the store. One disutility of shopping online is the delivery fee $p$. Another disutility of the e-grocery channel is related to the inconvenience of waiting for the groceries to arrive (e.g., lead time, number of time windows, length of the time window). Let $w(0 \leq w \leq 1)$ denote the disutility with respect to waiting time of delivery, where $w=0$ is the highest level of disutility and $w=1$ is the lowest. Then the overall utility of the e-grocery channel can be written as

$$
u_{e}=\beta v-\tau^{p} p-\tau^{w}(1-w)
$$

where $v$ is the valuation of the channel for having groceries at home and $\beta$ is a multiplier that captures the general customer preference for the e-grocery channel, which is due to such factors as convenience. The values of the parameters $\tau^{p}$ and $\tau^{w}$ (with $\tau^{p}, \tau^{w}>0$ ) reflect the sensitivity of the customer to (respectively) the delivery fee and the waiting time.

In line with the literature (e.g., Forman et al. 2009, Chintagunta et al. 2012), we suppose that travel time and transportation costs are the main disutilities of visiting the physical store. There is much empirical evidence suggesting that customers are more likely to shop online when they live farther away from a physical store (Cachon 2014). We model the average distance to a store in relation to the store density. With increases in the number $N_{s}^{s}$ of retailer's stores, the average distance of a customer to the nearest store decreases - thereby boosting the store channel's utility. Let $\delta_{s}^{s}=N_{s}^{s} / A$ be the density of stores in the retailer's store channel. We follow Cachon in approximating the average round-trip distance, $\phi_{t} / \sqrt{\delta_{s}^{s}}$, under the assumption that all customers in the store's service area purchase from the retailer's nearest store. The overall utility of the store channel, $u_{s}$, can be defined as follows:

$$
u_{s}=\alpha v-\frac{\phi_{t}}{\sqrt{\delta_{s}^{s}}}
$$

where $\phi_{t}$ depends on the shape of the area. The parameter $\alpha$ (with $\alpha>0$ ) determines the customer preference for the store channel that is due to such factors as assortment, freshness, environmental concerns, Internet connectivity and speed, and the hours during which stores are open. Hence $\beta / \alpha$ captures the relative popularity of the e-grocery channel over the store channel. 
The customer has the choice of an outside option whose utility is $u_{o}$. Since the outside option is represented by the stores not belonging to our retailer, it follows that the utility of that option is affected only by the customer's cost of traveling to a store. Therefore,

$$
u_{o}=(\beta+\alpha) v-\frac{\phi_{t}}{\sqrt{\delta_{o}^{s}}} .
$$

In this expression, $\delta_{o}^{s}=N_{o}^{s} / A$ is the density of grocery stores not belonging to the retailer, with $N_{o}^{s}=N^{s}-N_{s}^{s}$. The multiplier $(\beta+\alpha)$ of the valuation of the outside option is chosen such that, in absence of other costs, a customer chooses the retailer and the outside option with equal probability.

We use the attraction demand model (Gallego et al. 2006) to determine the probability of choosing channel $i \in\{e, s, o\}$, where $\gamma_{i}=u_{i} / \sum_{i} u_{i} ; u_{o}=0$ corresponds to the monopolistic setting in which there is no outside option. The number of customers choosing a channel $i$ to purchase groceries is given by $N_{i}^{h}=\gamma_{i} N^{h}$.

\subsection{Cost model}

The store channel is characterized by low variable fulfillment costs and high fixed costs. The costs of serving an additional customer are negligible in the supermarket context. In contrast, the egrocery channel is characterized by high variable costs that stem from order picking and last-mile delivery operations. For each sales channel, we view the supply of products to the stores and to the e-fulfillment warehouses as fixed costs that are not associated with specific customer orders. So in line with common management accounting practice, we focus on the variable costs and the contribution margin

\subsubsection{E-grocery channel}

The customer orders grocery products that must then be picked and packed into bags or crates for delivery. Picking grocery products is challenging because they require different temperature zones and are both fragile and bulky. Different customer orders are often picked in parallel, and the picking time per order depends on the general picking setup (warehouse or store) and level of automation (Kämäräinen et al. 2001, Hübner et al. 2016). In modeling this dynamic, we use $c^{p}$ to denote the picking cost per order.

Next we consider the costs of the last-mile delivery from an e-grocery fulfillment center to the customer home. The fulfillment center operates a fleet of homogeneous vehicles, each with a capacity of $Q$ orders. We assume there is only one vehicle per shift and consider a single shift per day. Hence the number of vehicles that the e-grocery channel needs for delivering to $N_{e}^{h}$ households is given by $N_{e}^{h} / Q$. Each vehicle has a cost $c^{v}$ that reflects leasing and depreciation expenses. We assume 
that the vehicle fleet and associated costs can vary with the number of customers, since the size of the (leased) fleet can be adjusted. We use $c^{l}$ to denote the per-vehicle labor cost of loading orders into the vehicle.

A delivery route consists of three parts: (i) the "stem" distance between the e-fulfillment center and the delivery area; (ii) the travel distance between consecutive customers within the delivery area; and (iii) the service times spent at the customers. We approximate the expected travel distance per route based on the customer density (as in Beardwood et al. 1959, Daganzo 1984). For a fulfillment center that is located in the center of a roughly circular service area of size $A$, we can estimate the stem distance as $\frac{2}{3} \phi_{k} \sqrt{A / \pi}$; here $\phi_{k}$ depends on the shape of the region (Daganzo 2005). The e-grocery channel has an effective household density of $\gamma_{e} \delta^{h}$. Hence the total inter-customer distance traversed in a route is estimated as $\phi_{k}(Q-1) / \sqrt{\gamma_{e} \delta^{h}}$.

Time-window constraints influence the effective spatial density. Multiple narrow time windows require the delivery vehicle to visit the same area multiple times, which means that the density is spread out over time. We use the time windows offered for delivery as a proxy for $w$, the disutility due to the waiting time for delivery. The higher the number of time windows, the lower the disutility. To incorporate this effect into our cost model, we multiply the household density by $w$; then the inter-customer distance becomes $\phi_{k}(Q-1) / \sqrt{\gamma_{e} \delta^{h} w}$. When disutility $w$ declines, the inter-customer distance increases because the effective customer density is reduced. The total distance traversed in all routes is therefore

$$
d=\left(\frac{4}{3} \phi_{k} \sqrt{\frac{A}{\pi}}+\phi_{k} \frac{Q-1}{\sqrt{\gamma_{e} \delta^{h} w}}\right) \frac{N_{e}^{h}}{Q} .
$$

The costs related to the travel distance comprise fuel costs and labor costs for the driver. In developed markets, labor accounts for the bulk of all travel costs. Let $c^{t}$ denote the labor and fuel costs per kilometer $(\mathrm{km})$ of driving. Combining the fixed cost of a vehicle and its loading cost, we can express the total travel cost associated with routes as

$$
c^{d}=\left(c^{v}+c^{l}+\frac{4}{3} \phi_{k} \sqrt{\frac{A}{\pi}} c^{t}+\phi_{k} \frac{Q-1}{\sqrt{\gamma_{e} \delta^{h} w}} c^{t}\right) \frac{N_{e}^{h}}{Q} .
$$

A customer order typically consists of several bags or crates of groceries, often sorted by the required product temperature zones. For delivery to the customer, we let $c^{s}$ represent the servicetime cost per order, which reflects the labor costs associated with the service time.

When we combine these cost components, the total cost of distribution (picking cost + transport cost + service cost) for the e-grocery channel is

$$
C_{e}=c^{p} N_{e}^{h}+c^{d}+c^{s} N_{e}^{h}
$$


We can now use (6) to write the distribution cost per order as

$$
\bar{C}_{e}=\frac{C_{e}}{N_{e}^{h}} \approx f^{v}+c^{p}+c^{s}+\frac{\phi_{k}}{\sqrt{\gamma_{e} \delta^{h} w}} c^{t}
$$

where $f^{v}$ represents the fixed cost per order depending on the vehicle capacity $Q$ and shape of the distribution region.

\subsubsection{Store channel}

For the store channel, most operational costs (e.g., real estate, store labor) are fixed. Stores generally have full-truckload deliveries, so we can assume that each store's distribution costs are fixed. Labor is a high fixed cost for all supermarket operations (MMC Retail Wholesale Industry Group 2019 2019, Campbell 2021). In the store channel, the average replenishment size of a store is fixed; hence warehouse picking costs are also fixed for stores of a given size. Therefore, our model assumes that there are no variable fulfillment costs associated with the store channel.

\subsection{Contribution margin and strategies}

We focus on maximizing the contribution margin - that is, the gross margin minus the variable costs. Recall that $m_{e}$ and $m_{s}$ represent the gross margin per order for (respectively) the e-grocery and store channels. The customer choice model gives the total demand for the e-grocery channel as $N_{e}^{h}=\gamma_{e} N^{h}$. So given the cost model (6), we can write the total contribution margin of the e-grocery channel as $\Pi_{e}=\left(m_{e}+p\right) N_{e}^{h}-C_{e}$. For the store channel, the variable costs per order are negligible and so its contribution margin is $\Pi_{s}=m_{s} N_{s}^{h}$.

The total contribution margin for the retailer is given by $\Pi=\Pi_{e}+\Pi_{t}$. The contributions per

order are denoted by $\bar{\Pi}, \bar{\Pi}_{e}$, and $\bar{\Pi}_{t}$ for (respectively) the retailer, the e-grocery channel only, and the store channel only. (We shall often use "contribution" as shorthand for "contribution margin" when our meaning is clear from the context.)

We consider two different strategies. In the first strategy, the retailer maximizes the contribution margins of the e-grocery and store channels independently - which for our purposes amounts simply to maximizing the e-grocery's contribution only. We refer to this as the online strategy. In the second, omni-channel strategy, the retailer jointly maximizes the contributions from both channels. The online strategy corresponds to the case where a retailer manages its different sales channels independently, which is a widespread practice. We seek to derive the optimal e-grocery delivery fee that either maximizes the contribution margin from the e-grocery channel alone ("online") or maximizes the total contribution margin ("omni-channel"). 


\section{Analytical results}

This section presents some analytical results that help us better understand the different trade-offs and interactions. The proofs of Propositions 1, 2, and 3 are given in (respectively) Appendix A, B, and $\mathrm{C}$.

Proposition 1. There exists a unique optimal delivery fee $p^{*}$ that maximizes the contribution margin.

Proof Please see Appendix A

Maximizing the contribution amounts to balancing the delivery fee's effect on revenues and costs. A lower fee corresponds to less revenue per customer but also creates more demand. And more demand, which yields economies of scale in last-mile delivery, leads to lower marginal costs per customer.

Proposition 2. The optimal market share of the e-grocery channel is lower under the omni-channel strategy than under the online strategy.

Because the e-grocery channel's market share declines with a higher delivery fee, Proposition 2 implies also that the optimal delivery fee $p^{*}$ is lower for the online strategy than for the omnichannel strategy. The reason is that the omni-channel strategy makes an explicit trade-off between the advantages of gaining more market share from the competition and the disadvantages of cannibalizing the retailer's own store channel by drawing customers from the profitable stores to the less profitable e-grocery channel.

We are unfortunately not able to derive a closed-form expression for the optimal delivery fee owing to the nonlinear nature of our cost and demand modeling. However, we can analyze the break-even delivery fee to understand how it behaves in relation to our key parameters. Since the margins are low, we expect that the behavior of the break-even delivery fee will be similar to that of the optimal fee. Let the break-even delivery fee $p^{b}$ be the delivery fee at which the marginal revenues of the e-grocery channel are equal to its marginal costs, and let $p^{0}$ be the minimum delivery fee at which no customer will choose to shop at the e-grocery channel. The optimal delivery fee $p^{*}$ is bounded by these two extremes; that is, $p^{b} \leq p^{*} \leq p^{0}$. To determine $p^{0}$, we set $u_{e}=0$ in (1). Then $p^{0}=\frac{\beta v+\tau^{w}(1-w)}{\tau^{p}}$.

Proposition 3. For the e-grocery channel, the break-even delivery fee $p^{b}$

(i) decreases with the household density, $\delta_{e}^{h}=N_{e}^{h} / A$;

(ii) increases with the picking costs per order, $c^{p}$; and

(iii) increases with the store density of the store channel, $\delta_{s}^{s}$.

It makes sense that the delivery fee required to break even increases with the costs per order of the e-grocery channel, which include both picking costs and distribution costs; the additional revenue 
from the delivery fee is needed to offset the costs. Less intuitive is that the break-even delivery fee increases with higher store densities. We can better understand this outcome by recognizing that the online market share decreases with the store density as the e-grocery channel becomes relatively less attractive. Fewer online orders reduce drop densities and hence the economies of scale in last-mile delivery, thus leading to higher fulfillment costs per order. Then the revenue loss from lowering delivery fees is greater than the cost reduction from serving more customers. We conclude that the retailer should increase its delivery fee at higher store densities.

\section{Numerical analysis}

To estimate our parameters, we use real-world data from the grocery industry together with social and demographic statistics. In this section we present the results of a series of numerical experiments based on those parameters. Our numerical study offers insights into the relative magnitude of effects of different parameters and into the conditions necessary for profitable growth of the egrocery market. When deriving the optimal solution, we enumerate the delivery fee's possible values $\left(p^{b} \leq p^{*} \leq p^{0}\right)$. Because we use realistic values, our study also provides insights into the long-run profitability and expected market shares of the e-grocery channel.

\subsection{Parameter estimates}

Table 1 reports our estimates for the parameters of the customer choice and operational cost model described in Section 3. The estimates are based on data from the Netherlands. We use public sources but have verified the estimates with several major Dutch online grocery retailers. 
Table 1 Model parameters

\begin{tabular}{|c|c|c|c|}
\hline Parameter & Notation & $\begin{array}{l}\text { Baseline } \\
\text { value }\end{array}$ & Sources \\
\hline $\begin{array}{l}\text { Preference of customer for } \\
\text { store channel }\end{array}$ & $\alpha$ & 2.8 & $\begin{array}{l}\text { Authors' estimate based on } \\
\text { current prices and market } \\
\text { shares }\end{array}$ \\
\hline Sensitivity to delivery fee & $\tau^{p}$ & 2.4 & $\begin{array}{l}\text { Authors' estimate based on } \\
\text { current prices and market } \\
\text { shares }\end{array}$ \\
\hline $\begin{array}{l}\text { Sensitivity of customer to ser- } \\
\text { vice quality w.r.t time }\end{array}$ & $\tau^{w}$ & 5.0 & $\begin{array}{l}\text { Authors' estimate based on } \\
\text { current prices and market } \\
\text { shares }\end{array}$ \\
\hline Picking cost per order & $c^{p}$ & $€ 12.5$ & $\begin{array}{l}\text { Reinhardt (2001), Moons } \\
\text { et al. (2019), Ehrler et al. } \\
(2019)\end{array}$ \\
\hline Service time cost per order & $c^{s}$ & $€ 4.2$ & $\begin{array}{l}\text { Drive (2018), Yang et al. } \\
(2014)\end{array}$ \\
\hline Annual cost per vehicle & $c^{v}$ & $€ 19,000$ & Schonewille (2016) \\
\hline Loading cost per vehicle & $c^{l}$ & $€ 8.3$ & $\begin{array}{l}\text { Punakivi and Saranen (2001), } \\
\text { Moons et al. (2019) }\end{array}$ \\
\hline Vehicle capacity in orders & $Q$ & 18 & Industry partner data \\
\hline$\phi_{k}$ & & 1.32 & Daganzo (1984) \\
\hline Cost per km & $c^{i}$ & $€ 1.8$ & $\begin{array}{l}\text { Statista (2020a), Mock } \\
\text { (2014), Moons et al. (2019) }\end{array}$ \\
\hline Gross margin & $m_{e}, m_{s}$ & $13 \%$ & $\begin{array}{l}\text { Marshoek (2018), Galante } \\
\text { et al. (2013) }\end{array}$ \\
\hline
\end{tabular}

To model demand, we consider a weekly cycle because it corresponds to the typical online grocery shopping cycle (Statista 2019). We model the operating costs per shift while assuming that weekly demand is spread equally across six shifts. Weekly spending on groceries is about $€ 100$ per household in the Netherlands (Nibud 2021). For grocery products, we assume a gross margin of $13 \%$ (Galante et al. 2013, Marshoek 2018) irrespective of the channel (so $m_{e}=m_{s}$ ). This assumption is reasonable since empirical evidence on the impact of different order patterns online and offline is not conclusive (Kacen 2003, Belavina et al. 2017, Acosta 2020). We consider a disutility cost of $€ 4$ per kilometer traveled per store visit; this cost reflects opportunity and fuel costs as well as urban travel speeds (Mock 2014, Schonewille 2016, Belavina et al. 2017, Statista 2020a).

Now we evaluate fulfillment costs in the e-grocery channel. Estimates from OW Robots (2021a) indicate that it takes some 30 minutes to pick a grocery order in a "manual" warehouse setting. At an average hourly wage of $€ 25$ (Moons et al. 2019), this time corresponds to picking costs of $€ 12.5$ per order. For the last-mile distribution operations, we consider the labor cost, fuel costs, and vehicle cost. We use a yearly fixed cost of $€ 19,000$ per vehicle for leasing and damage costs (Schonewille 2016). The number of vehicle trips needed depends on the number of orders per vehicle trip. The maximum number of orders per vehicle depends on the their size (i.e., volume and weight) in relation to vehicle capacity. For an average order of $€ 100$, we assume a vehicle capacity 
$Q$ of 18 orders. We assume an average loading time of 20 minutes per vehicle trip (Punakivi and Saranen 2001, Moons et al. 2019), which corresponds to a loading cost of $€ 8.3$ per vehicle. The delivery costs per kilometer - based on urban speed, fuel consumption, and labor costs - is $€ 1.8$. We further assume an average service time at the customer of 10 minutes, which is consistent with our industry partner's experience and that of other European retailers offering service "up to the kitchen table" (Klein et al. 2019). Using the average hourly wage of a driver, we obtain a service cost of $€ 4.2$.

To fit the utilities of shopping online and in the store as well as the price sensitivity with respect to delivery fees, we compare the market shares of two competing grocery retailers in the Dutch market: Albert Heijn Online and Picnic (Statista 2020b, 2021). Whereas Picnic offers its customers free delivery but with no time-window choice, AH Online charges a delivery fee of about $€ 8$ yet offers more delivery time windows. The product prices are similar at the two grocers (Els 2017). We estimate price sensitivity parameters based on these observed combinations of delivery fees and market share.

Next we shall vary the household and store densities to generate insights into how these aspects affect overall online performance.

\subsection{Impact of household density and store density}

In our first set of experiments, we find the delivery fees and corresponding online market shares that maximize the e-grocery channel's contribution margin for different household densities and store densities (i.e., under the "online" strategy). Panel (a) of Figure 1 shows the profit per order for the e-grocery channel; panels (b) and (c) plot the corresponding market shares and delivery fee, respectively.

In these experiments, we vary the household density between 1,000 per $\mathrm{km}^{2}$ and 7,000 per $\mathrm{km}^{2}$. We consider the household density because it is more commonly used, than is population density, to model grocery shopping. For reference, Rotterdam (the Netherlands) has nearly 1,400 households per $\mathrm{km}^{2}$, which corresponds to a population density of 2,900 per $\mathrm{km}^{2}$ (Rotterdam-Partners 2018, Statista 2020c); Seoul (South Korea) has a household density of 6,600 per $\mathrm{km}^{2}$ for a population density of 16,700 per km² (Statistics Korea 2016, City Mayors Statistics 2018). We similarly vary the store density from 1 to 7 per $\mathrm{km}^{2}$.

Looking at the impact of household density, we see that the e-grocery channel's profitability (Figure 1a) increases with household density. A greater number of households per square kilometer results in smaller inter-customer distances and thus lower fulfillment costs per order. This cost reduction has a positive effect on the e-grocery channel's profitability. Hence the e-grocery market share increases also with household density (Figure 1b) because the lower fulfillment costs enable 
(a) Online profit per order $(€)$

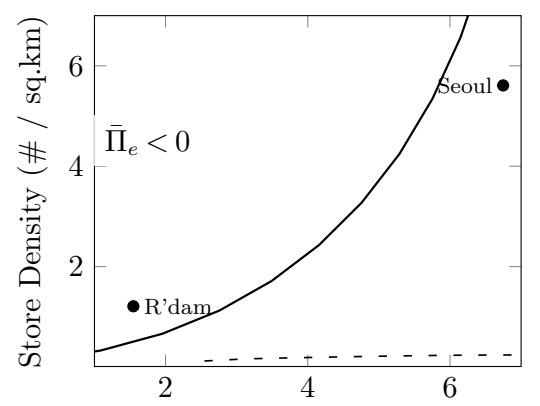

Household Density $\left(x 10^{3} / \mathrm{sq} \cdot \mathrm{km}\right)$

$$
-\bar{\Pi}_{e}=0.0--\bar{\Pi}_{e}=0.5
$$

(c) Online delivery fee $(€)$

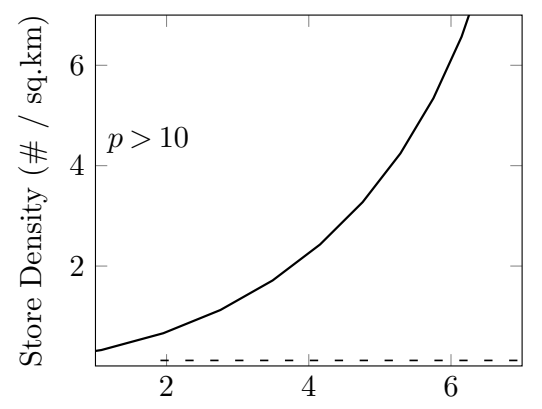

Household Density (x10 / sq.km) (b) Online market share (\%)

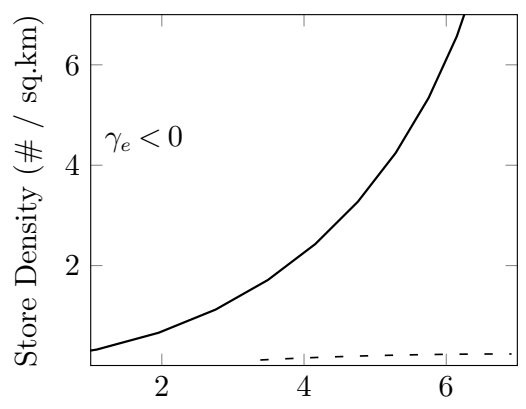

Household Density(x10 / sq.km)

$$
-\gamma_{e}=0 \%-\gamma_{e}=5 \%
$$

Figure 1 Online profitability versus household density and store density for the online strategy

lower delivery fees (Figure 1b). This dynamic is consistent with the analytical results (presented in Section 4) for the break-even delivery fee. We can see that, at lower household densities, the unit profits are negative and so the retailer might as well shut down the e-grocery channel (zero market share) by way of charging an exorbitant delivery fee. These results reveal that per-unit profitable e-grocery operations are possible only for higher household densities. In particular, the e-grocery channel generates losses for all combinations of household and store densities to the left of the figure's $\bar{\Pi}=0.0$ line.

For the city of Rotterdam, which has one of the highest household densities in the Netherlands, our results indicate that per-unit profitability is impossible. Indeed, real-world evidence suggests that none of the Dutch online grocers is currently profitable (NU.nl 2020, RTL Nieuws 2021). One reason for the relatively low online market shares and profitability is that store density in the Netherlands is high (Belderok et al. 2019). According to various surveys of Dutch shoppers, the argument given most often for not buying food online is that there is already a supermarket close to their home (Statista 2021).

As for the impact of store density on the e-grocery channel's profitability, we see that the latter decreases with the store density. At high store densities, the average distance between the 
store and the consumer is small, which makes the store channel more attractive and hence more competitive. For example, the US grocery retailer Trader Joe's recently discontinued its delivery services in New York City, citing the high story density and being "already [in] close proximity to customers" as compelling reasons. Only at very low store densities and high household densities $\left(>2,500\right.$ households per $\mathrm{km}^{2}$ ) do we observe higher market shares and profits per order. Despite the theoretical interest of this result, high household densities are in fact often associated with high store densities (McGuirt et al. 2015). Figure 1a also shows where Rotterdam (our baseline city) and Seoul (another high-density city) are located on the graph in terms of their household and store density.

Figure 1c illustrates that the delivery fee increases with the store density. This outcome is consistent with our analytical results and with a recent study of Capgemini (2019). These findings indeed suggest that the optimal fee behaves similarly to the break-even delivery fee, as the contribution margin per order is generally low for the e-grocery channel and there is little room for reducing the delivery fee in order to protect the retailer's online market share. Our results indicate that an average delivery fee of at least $€ 8$ is needed to be profitable. In the United Kingdom, which features a mature and competitive e-grocery market, we see that several grocery retailers charge a lower fee. Yet this observation is still consistent with our results because these e-groceries are, in effect subsidized and do not generate any profits (Eley 2020). The positive relationship between store density and the delivery fee depends on $\beta / \alpha$, or the relative consumer preferences for each sales channel. We discuss (in Section 5.4) how this result is affected by changed consumer preferences.

In the next set of experiments, we consider the omnichannel strategy in which we explicitly model the interaction between the different channels and maximize the joint contribution of the e-grocery and store channel of a single grocery retailer.

Under the omni-channel strategy, it is not profitable to operate the e-grocery channel in any scenario - even when household density is high and store density is low. Although adding the egrocery channel may help boost the retailer's overall market share, that benefit does not offset the costs of cannibalizing sales from its own store channel. The reason is that the effective contribution margins of the e-grocery channel are lower than those of the store channel, a difference that is due to the additional revenues from the delivery fee failing to offset the high online fulfillment costs. The implication is that, in the short term, online sales reduce the omni-channel retailer's overall profitability. Some grocery retailers (e.g., Albert Heijn) have acknowledged this reality. For that reason, grocery discounters such as Lidl have decided not to open an e-grocery channel: "The costs of going online just don't add up" (Lidl's UK in the CEO, Christian Härtnagel, quoted in Retailweek 2021). 


\subsection{Impact of household density and picking costs}

Picking is one of the main cost drivers in the e-grocery channel. A recent study by McKinsey (Kuijpers et al. 2018) suggests that the best retailers can achieve picking costs of $€ 5$ per order at a dedicated pick location. Grocery retailer Ocado claims that heavy warehouse automation enables it to pick a 50-item order in 10 minutes (Financial Times 2020, OW Robots 2021b, This Is Money 2021), which would correspond to even lower picking costs per order. Note that picking times in a regular supermarket are typically much longer. A recent empirical analysis by Vazquez-Noguerol et al. (2021) reports average picking times of 43 minutes per order in this context (the equivalent of about $€ 18)$. Here we study the impact of picking costs by varying that cost between $€ 0$ and $€ 12$ per order. Moreover, we vary the household densities because they are a key driver of last-mile distribution costs. We fix the store density to the base-case value of $1.2 / \mathrm{km}^{2}$.

Figure 2 plots the contribution margin per order for different household densities and picking costs for the online strategy. As expected, the profitability of the e-grocery channel decreases with picking costs. For the base case, the retailer's e-grocery channel is not profitable and breaks even only at an extremely high household density. At the current picking cost, even when household density increases, the retailer finds it suboptimal to lower its delivery fee and thereby increase market share - as shown in panel (b) of the figure. The primary reason for this outcome is that an order's contribution margin is negative at the current cost structure. The graph confirms that a retailer's online market share increases when picking costs are lower. So if the picking cost is $€ 5$ per order, for example, then online sales account for $10 \%$ of the retailer's total grocery market.

Warehouse automation can increase contribution margins by $8 \%$ by reducing the fulfilment cost (Capgemini 2019). However, this comes at very high investment costs of hundreds of millions of euros (Pooler 2018).

The positive effect of lower picking costs on the online market share is observed also in the omnichannel strategy. With a picking cost of $€ 12.5$ per order (as in Section 5.2), it is not profitable to operate the e-grocery channel for any store and household density combination. Yet when the picking cost is halved, the retailer benefits from operating an e-grocery channel alongside its store channel - provided that the household density is high enough (see Figure 3).

\subsection{Cannibalization of the store channel}

Our experiments based on current estimates for the costs and customer valuation across channels usually result in online market shares well below $10 \%$. We find that it is not profitable to operate an e-grocery channel when household density is low, which suggests that online grocery sales should not much affect the supermarket landscape. However, customer preferences may change over time. 
(a) Online profit per order $(€)$

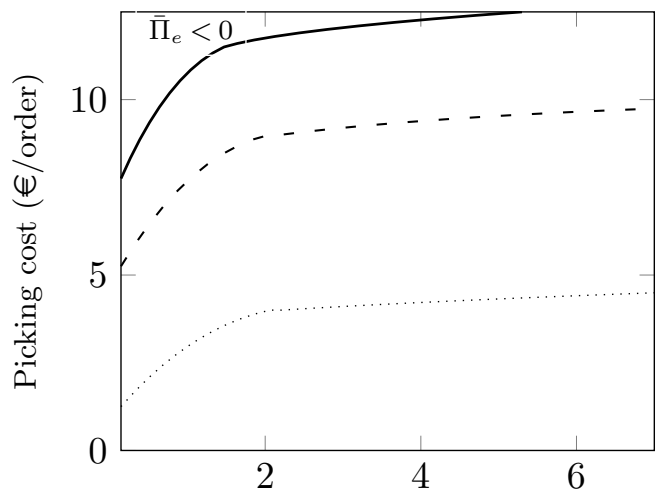

Household Density (x10 / sq.km) (b) Online market share (\%)

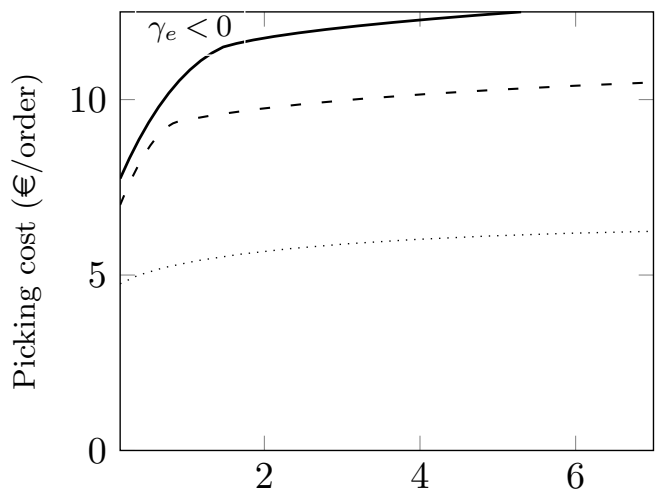

Household Density (x10³ / sq.km)

$-\bar{\Pi}_{e}=0.0--\bar{\Pi}_{e}=2.0 \cdots \cdots \cdot \bar{\Pi}_{e}=4.0$

$-\gamma_{e}=0.0--\gamma_{e}=5 \% \cdots \cdots \cdot \gamma_{e}=10 \%$

Figure 2 Online profitability versus household density and store density for the online strategy

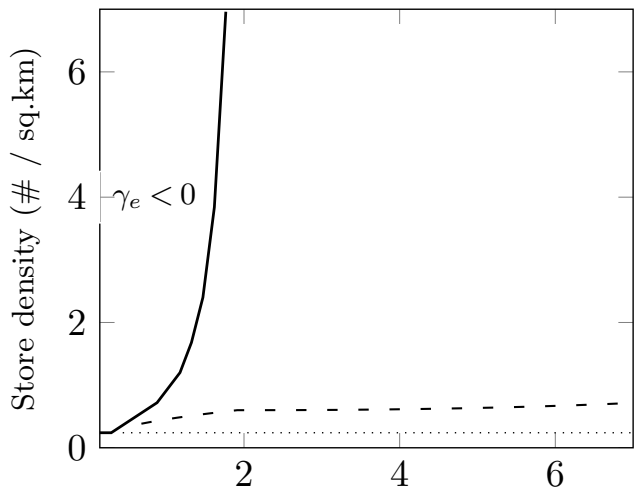

Household Density (x10 $/$ sq.km)

$$
-\gamma_{e}=0.0--\gamma_{e}=5 \% \cdots \cdots \cdot \gamma_{e}=10 \%
$$

Figure 3 Online market share for the omni-channel strategy (picking cost $=€ 6.25$ /order)

One pertinent example is that the long-term effect of the Covid-19 pandemic on grocery shopping preferences remains still unclear. We shall now explore the impact both of higher customer valuation and of lower picking costs on e-grocery market shares; our aim is to identify the point at which cannibalization by the e-grocery channel threatens the store channel's profitability.

Recall from our online utility function (1) that $\beta / \alpha$ captures customers' relative preference for the e-grocery channel over the store channel. A customer's willingness to pay for the e-grocery channel increases with $\beta$. To determine the break-even point, we estimate the fixed costs $F$ per store. The store channel's contribution is then $\Pi_{s}=m_{s} N_{s}^{h}-F N_{s}^{s}$. In view of the Dutch supermarket data from Marshoek (2018), we consider a cost $F$ of $€ 25,000$ per week for a store whose weekly revenue is between $€ 150,000$ and $€ 250,000$; this cost includes fixed labor, rent, and replenishment costs. From the same report, we obtain $13 \%$ as the gross product margin available to cover these costs. 
In Figure 4, panel (a) illustrates the regions in which the e-grocery and the store channel are not profitable under the online strategy - that is, while maximizing the e-grocery channel's contribution. We observe that, when the relative online valuation is low $(\beta / \alpha<0.35)$, the e-grocery channel is not profitable for scenarios with higher picking costs. The graph shows that, as picking costs rise, we need a greater valuation (and thus a higher delivery fee) to offset the costs. At the other end of the spectrum, we see that if online valuations are relatively high then the retailer should close its physical stores and operate only the e-grocery channel. For $\beta / \alpha>1.8$ (i.e., when online valuation is almost double the offline valuation), the market share of the store channel is too low to cover its fixed costs. Note that the corresponding optimal delivery fee in this case ranges between $€ 26$ and $€ 36$ for the e-grocery channel when $1.8<\beta / \alpha<3.0$. The optimal delivery fee increases with relative online valuation. We remark that these "optimal" delivery fees seem unrealistically high, which suggests that store closures via this mechanism are unlikely in the short term.

(a) Online strategy

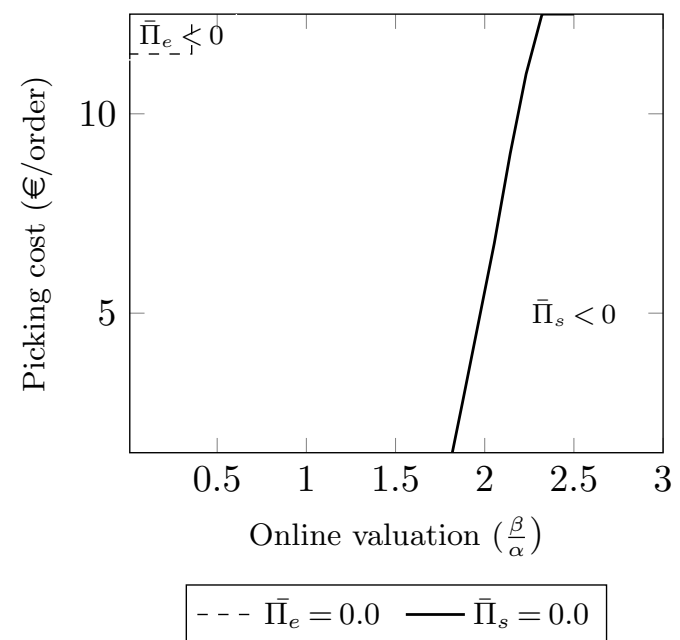

(b) Omnichannel strategy

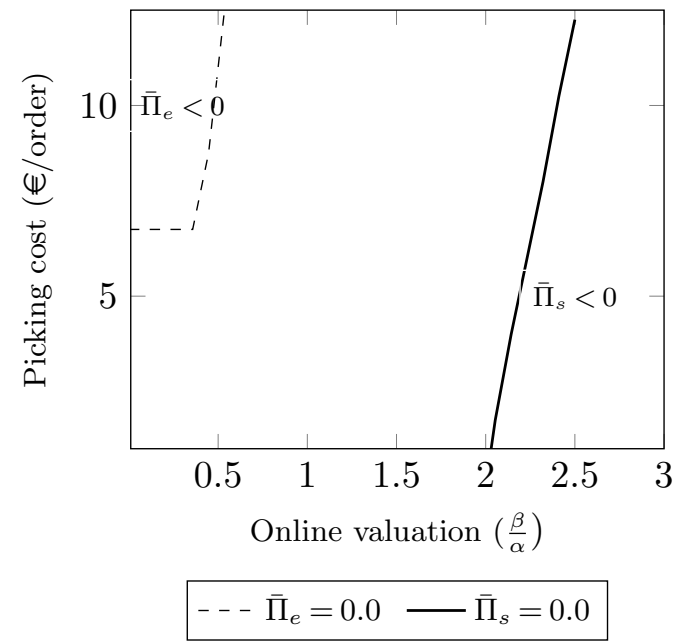

Figure 4 E-grocery and store channels' no-profit zones for different relative online valuations and picking costs

Panel (b) of Figure 4 shows similar no-profit zones for the e-grocery and store channels when the total contribution margin is maximized under the omni-channel strategy. Although similar trends are evident, the "tipping points" have shifted. In the omni-channel strategy, if picking costs exceed $€ 10$ then the e-grocery channel is not profitable when the relative online valuation is low $(\beta / \alpha<0.55)$. From the store channel perspective, unprofitability begins under higher relative online valuations $(\beta / \alpha>2.1)$. The corresponding optimal delivery fee is from $€ 30$ to $€ 41$ for the e-grocery channel when $2.1<\beta / \alpha<3.0$. In the omni-channel strategy, the interaction between the two channels comes into play. We conclude that, when the omni-channel strategy is pursued, it takes higher relative online valuations for the e-grocery channel to cannibalize sales of grocery stores to the extent that stores start generating losses. 


\section{Conclusion}

This study addresses the effect of household and store densities on the e-grocery channel's profitability. We develop a stylized model to capture the principal cost factors affecting customers' utility and hence their choice of channel when purchasing groceries. Whereas the delivery fee and service level (with respect to time) drive online utility, for the store channel a major factor is the cost of visiting the store. By assessing both customer choice behavior and operational costs, we generate insights into what drives the profitability and market shares of the different channels in their optimal settings. We use real-world data to estimate the model's parameters. This approach gives us a solid benchmark based on realistic scenarios - one against which we can compare the effects of relevant parameters on the resulting equilibria.

We find that the e-grocery channel becomes profitable with increasing household density and decreasing store density. The former's effect is due to reducing the distribution costs; the latter's effect stems from increasing the relative consumer disutility of using the e-grocery channel. The cost of picking individual orders in the e-grocery channel plays a crucial role in that channel's profitability. The e-grocery channel is not profitable at the cost structure estimate based on current industry data; this finding accords with current market conditions, where the e-grocery channel yields very low (or even negative) profitability. Considering the retailer's optimal overall strategy, we conclude that - for almost any realistic estimate of store and households density - it is never optimal to launch an e-grocery channel owing to its high operational costs.

It is clear that these basic insights can be strongly affected only by changes in the relative consumer preferences for the online channel. Substantial increases in the online channel's perceived value may induce consumers to pay much higher delivery fees. In that event, the store channel's market share could decline to the extent that the fixed cost of a store network cannot be recovered. Such high customer valuations may develop first in some specific markets.

Our results suggest three strategic paths toward profitability in e-grocery: service, niche, or subsidies. The service path requires a large increase in valuations of the online channel vis-à-vis the store channel without which it will be difficult for customers to accommodate themselves to paying higher delivery fees. In the United States, for example, this effect has been observed during the Covid-19 pandemic: many consumers appreciated the perceived health safety benefits of home delivery compared to visiting a store.

The niche path requires that the online channel focus on areas with high household density and low store density. In such areas, the relative costs of the online channel are most competitive and the valuation of the store channel is relatively low because of the travel costs to reach a store. These niches can be observed in many Chinese cities with very high household densities and very 
low supermarket density. For instance, Beijing has a population of about 20 million people but fewer than than 200 supermarkets. In comparison, the Netherlands is home to more than 2,000 supermarkets serving 17 million people; hence it is a much less attractive market environment for pursing a niche strategy.

The subsidy path relies on the deep pockets of investors and shareholders to subsidize the online channel until such time that physical stores can respond only by closing. This dynamic reduces the relative valuation of the store channel and thus allows the online channel to charge higher delivery fees. The subsidy path is a challenging one because it requires not only a longer-range perspective but also deep-pocketed investors willing to bet on some of the e-grocery "pure players". We expect to see more differentiation in strategies as the market develops.

\section{References}

Acosta, 2020. Online grocery shopping can help retailers increase their reach, boost impulse buys. https://www.smartbrief.com/original/2020/02/online-grocery-shopping-can-helpretailers-increase-their-reach-boost.

Agatz, N., Campbell, A., Fleischmann, M., Savelsbergh, M., 2011. Time slot management in attended home delivery. Transportation Science 45, 435-449.

Andrews, R.L., Currim, I.S., 2004. Behavioural differences between consumers attracted to shopping online versus traditional supermarkets: implications for enterprise design and marketing strategy. International Journal of Internet Marketing and Advertising 1, 38-61.

Ansari, S., Başdere, M., Li, X., Ouyang, Y., Smilowitz, K., 2018. Advancements in continuous approximation models for logistics and transportation systems: 1996-2016. Transportation Research Part B: Methodological 107, 229-252.

Balakrishnan, A., Sundaresan, S., Zhang, B., 2014. Browse-and-switch: Retail-online competition under value uncertainty. Production and Operations Management 23, 1129-1145.

Beardwood, J., Halton, J.H., Hammersley, J.M., 1959. The shortest path through many points, in: Mathematical Proceedings of the Cambridge Philosophical Society, Cambridge University Press. pp. $299-327$.

Begley, S., Marohn, E., Mikha, S., Rettaliata, A., 2020. Digital disruption at the grocery store. https://www.mckinsey.com/industries/retail/our-insights/digital-disruption-atthe-grocery-store.

Belavina, E., Girotra, K., Kabra, A., 2017. Online grocery retail: Revenue models and environmental impact. Management Science 63, 1781-1799.

Belderok, A., Einwachter, M., van Aalst, M., Winkelman, J., Veul, R., 2019. The Dutch grocery sector in 2030 - Roland Berger. https://www.rolandberger.com/publications/publication_pdf/ roland_berger_online_grocery_shopping.pdf. 
Bernstein, F., Song, J.S., Zheng, X., 2008. "bricks-and-mortar" vs. "clicks-and-mortar": An equilibrium analysis. European Journal of Operational Research 187, 671-690.

Boyer, K.K., Hult, G.T.M., 2005. Extending the supply chain: integrating operations and marketing in the online grocery industry. Journal of Operations Management 23, 642-661.

Boyer, K.K., Prud'homme, A.M., Chung, W., 2009. The last mile challenge: evaluating the effects of customer density and delivery window patterns. Journal of business logistics 30, 185-201.

Boysen, N., De Koster, R., Weidinger, F., 2019. Warehousing in the e-commerce era: A survey. European Journal of Operational Research 277, 396-411.

Breugelmans, E., Campo, K., Gijsbrechts, E., 2007. Shelf sequence and proximity effects on online grocery choices. Marketing Letters 18, 117-133.

Cachon, G.P., 2014. Retail store density and the cost of greenhouse gas emissions. Management Science 60, $1907-1925$.

Campbell, J., 2021. Is Owning a Grocery Store Profitable? (Not always Here's why). https:// thegrocerystoreguy.com/is-owning-a-grocery-store-profitable/.

Capgemini, 2019. The last-mile delivery challenge. https://www.capgemini.com/wp-content/uploads/ $2019 / 01 /$.

Capgemini, 2019. The last mile delivery challenge. https://www.capgemini.com/wp-content/uploads/

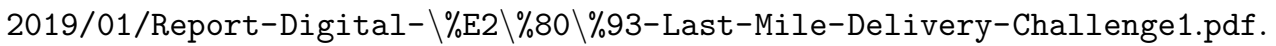

Castia, M., 2020. Ocado Group 2019 pretax loss widens despite growing revenue . https: //www.marketwatch.com/story/ocado-group-2019-pretax-loss-widens-despite-growingrevenue-2020-02-11.

Chintagunta, P.K., Chu, J., Cebollada, J., 2012. Quantifying transaction costs in online/off-line grocery channel choice. Marketing Science 31, 96-114.

City Mayors Statistics, 2018. The largest cities in the world by land area, population and density. http: //www.citymayors.com/statistics/largest-cities-density-125.html.

Colliers International, 2019. SUPERMARKET REPORT. https://www2.colliers.com/nl-nl/research/ 20190726supermarkten.

Daganzo, C.F., 1984. The length of tours in zones of different shapes. Transportation Research Part B: Methodological 18, 135-145.

Daganzo, C.F., 2005. Logistics systems analysis. Springer Science \& Business Media.

Danaher, P.J., Wilson, I.W., Davis, R.A., 2003. A comparison of online and offline consumer brand loyalty. Marketing Science 22, 461-476.

Dannenberg, P., Fuchs, M., Riedler, T., Wiedemann, C., 2020. Digital transition by covid-19 pandemic? the german food online retail. Tijdschrift voor economische en sociale geografie 111, 543-560. 
Drive, G., 2018. Peeking inside the pod: A deep look inside Peapod's grocery delivery business. https://www.grocerydive.com/news/grocery--peeking-inside-the-pod-a-deep-lookinside-peapods-grocery-delivery-business/533816/.

Ecommerce News Europe, 2019. Picnic raises $€ 250$ million for robotized distribution center. https:// ecommercenews.eu/picnic-raises-e250-million-for-robotized-distribution-center/.

Edwards, J., 2016. HSBC makes a huge, counterintuitive call: Online grocery delivery is 'the emperor's new clothes'. https://www.businessinsider.in/hsbc-makes-a-huge-counterintuitive-callonline-grocery-delivery-is-the-emperors-new-clothes/articleshow/51313570.cms?mobile= no.

Ehrler, V.C., Schöder, D., Seidel, S., 2019. Challenges and perspectives for the use of electric vehicles for last mile logistics of grocery e-commerce-findings from case studies in germany. Research in Transportation Economics, 100757.

Eley, J., 2020. Why uk supermarkets are not making super profits. URL: https://www.ft.com/content/ $1011469 b-65 f 2-4 c a 7-83 a c-8 c 4921 f c f 6 c 5$.

Els, v.A., 2017. How cheap is online supermarket Picnic really? We took the test. https:// www.businessinsider.nl/hoe-goedkoop-online-supermarkt-picnic-nou-echt-deden-de-test/.

Financial Times, 2020. Why supermarkets are struggling to profit from the online grocery boom\%. https: //www.ft.com/content/b985249c-1ca1-41a8-96b5-0adcc889d57d.

FMI, Nielsen, Dialogic Group LLC, 2020. The Omnishopper Imperative for Food Retailers. https://www.fmi.org/forms/store/ProductFormPublic/the-omnishopper-imperative-forfood-retailers.

Forman, C., Ghose, A., Goldfarb, A., 2009. Competition between local and electronic markets: How the benefit of buying online depends on where you live. Management science 55, 47-57.

Galante, N., López, E.G., Monroe, S., 2013. The future of online grocery in Europe. https: //www.mckinsey.com/ /media/McKinsey/Industries/Retail/Our $\ \% 20$ Insights/The $\backslash \% 20$ future $\backslash \%$ $20 \circ \backslash \% 20$ online $\backslash \% 20$ grocery $\backslash \% 20$ in $\backslash \% 20$ Europe/The_future_of_online_grocery.ashx.

Gallego, G., Huh, W.T., Kang, W., Phillips, R., 2006. Price competition with the attraction demand model: Existence of unique equilibrium and its stability. Manufacturing \& Service Operations Management 8, $359-375$.

Gao, F., Agrawal, V.V., Cui, S., 2021. The effect of multichannel and omnichannel retailing on physical stores. Management Science .

Harsha, P., Subramanian, S., Ettl, M., 2019. A practical price optimization approach for omnichannel retailing. Informs Journal on Optimization 1, 241-264.

Hays, T., Keskinocak, P., De López, V.M., 2005. Strategies and challenges of internet grocery retailing logistics, in: Applications of supply chain management and e-commerce research. Springer, pp. 217-252. 
Huang, J., Leng, M., Parlar, M., 2013. Demand functions in decision modeling: A comprehensive survey and research directions. Decision Sciences 44, 557-609.

Hübner, A.H., Kuhn, H., Wollenburg, J., Towers, N., Kotzab, H., 2016. Last mile fulfilment and distribution in omni-channel grocery retailing: a strategic planning framework. International Journal of Retail \& Distribution Management .

Kacen, J., 2003. Bricks \& clicks \& the buying impulse: An investigation of consumer impulse buying behaviour in an online and a traditional retail environment. European Advances in Consumer Research 6, 271-276.

Kämäräinen, V., Småros, J., Holmström, J., Jaakola, T., 2001. Cost-effectiveness in the e-grocery business. International Journal of Retail \& Distribution Management .

Klein, R., Neugebauer, M., Ratkovitch, D., Steinhardt, C., 2019. Differentiated time slot pricing under routing considerations in attended home delivery. Transportation Science 53, 236-255.

de Koster, R.M.B., 2002. Distribution structures for food home shopping. International Journal of Physical Distribution \& Logistics Management 32, 362-380.

Kuijpers, D., Simmons, V., Van Wamelen, J., 2018. Grocery Stores Industry Profitability. https://www.mckinsey.com/industries/retail/our-insights/reviving-grocery-retailsix-imperatives.

Kull, T.J., Boyer, K., Calantone, R., 2007. Last-mile supply chain efficiency: an analysis of learning curves in online ordering. International Journal of Operations \& Production Management .

Lin, I.I., Mahmassani, H.S., 2002. Can online grocers deliver?: Some logistics considerations. Transportation Research Record 1817, 17-24.

Marshoek, 2018. Benchmark Supermarketen 2018. https://www.marshoek.nl/file/download/default/ C371F8D049EA6B023266DB9D1C7FFBD4/Totaal $\backslash \% 20 B e n c h m a r k ~ \ \% 20-\backslash \% 20 R a p p o r t \backslash \% 20 v e r s i e \backslash \%$ $2022 \backslash \% 20$ mei.pdf.

McGuirt, J.T., Pitts, S.B.J., Ammerman, A., Prelip, M., Hillstrom, K., Garcia, R.E., McCarthy, W..J., 2015. A mixed methods comparison of urban and rural retail corner stores. AIMS Public Health 2, 554.

MMC Retail Wholesale Industry Group, 2019. FIGHTING FOR THE FUTURE OF THE SUPERMARKET INDUSTRY. https://www.oliverwyman.com/our-expertise/insights/2019/dec/retailconsumer-journal-vol-7/fighting-for-the-future-of-the-supermarket-industry.html.

Mock, P., 2014. Eu co2 standards for passenger cars and light-commercial vehicles. International Council on Clean Transportation , 1-9.

Moons, S., Braekers, K., Ramaekers, K., Caris, A., Arda, Y., 2019. The value of integrating order picking and vehicle routing decisions in a b2c e-commerce environment. International Journal of Production Research 57, 6405-6423.

Nibud, 2021. What do I spend on food? https://www.nibud.nl/consumenten/wat-geeft-u-uit-aanvoeding/. 
NPD, 2018. U.S. Consumers Take an Omnichannel Approach When It Comes to Grocery Shopping. https://www.npd.com/wps/portal/npd/us/news/press-releases/2018/us-consumerstake-an-omnichannel-approach-when-it-comes-to-grocery-shopping/.

NU.nl, 2020. Boodschappen bezorgen is voor albert heijn nog steeds geen goudmijn. URL: https://www.nu.nl/economie/6079344/boodschappen-bezorgen-is-voor-albert-heijn-nogsteeds-geen-goudmijn.html.

OW Robots, 2021a. Picking rates across the sectors: Where do you stand? https://www.owrobotics.co.uk/ 2021/02/08/picking-rates-across-the-sectors-where-do-you-stand/.

OW Robots, 2021b. Welcome to the automated warehouse of the future - How British supermarket Ocado is using robots to make online grocery shopping faster. https://www.theverge.com/2018/5/8/17331250/ automated-warehouses-jobs-ocado-andover-amazon.

Park, S., 2020. Online grocery store operator Kurly attracts $\$ 163 \mathrm{mln}$ investment. http:// www.ajudaily.com/view/20200508153352194.

Pooler, M., 2018. Robots gain ground in ecommerce warehouses. URL: https://www-ftcom.eur.idm.oclc.org/content/a7e8d282-e0e1-11e7-a0d4-0944c5f49e46.

Punakivi, M., Saranen, J., 2001. Identifying the success factors in e-grocery home delivery. International Journal of Retail \& Distribution Management .

Ramus, K., Nielsen, N.A., 2005. Online grocery retailing: what do consumers think? Internet research .

Reinhardt, 2001. Tesco Bets Small-and Wins Big. https://www.bloomberg.com/news/articles/2001-0930/tesco-bets-small-and-wins-big.

ResearchAndMarkets.com, 2020. Global online grocery market: Insights \& forecast with potential impact of covid-19 (2020-2024). https://www.researchandmarkets.com/reports/2311034/. [Online; accessed June 30 2021].

Retailweek, 2021. Lidl boss: The costs of going online just don't add up. https:// www.retail-week.com/grocery/lidl-boss-the-costs-of-going-online-just-dont-add-up/ 7036689.article?authent=1.

Rotterdam-Partners, 2018. Facts \& Figures Rotterdam General. https://rotterdammakeithappen.nl/en/ media-objects/facts-figures-rotterdam-general/.

RTL Nieuws, 2021. Overvol op markt voor online supers; kunnen ze wel winst maken? URL: https://www.rtlnieuws.nl/economie/bedrijven/artikel/5217367/online-supermarktwebwinkel-crisp-picnic-albertheijn-jumbo-plus.

Schonewille, G.A., 2016. Calculation of transport cost for freight carriers on the last mile: Conducting a case study in the municipality of delft to validate and improve usage of the last-mile scan calculation model. 
Seow, C., Delaney-Klinger, K., Boyer, K.K., Frohlich, M., 2003. The return of online grocery shopping: a comparative analysis of webvan and tesco's operational methods. The TQM Magazine .

Statista, 2019. How often do you order foodstuffs online? https://www.statista.com/statistics/ 1023847/frequency-of-ordering-foodstuffs-online-in-the-netherlands/.

Statista, 2020a. Average prices of diesel fuel in the Netherlands from 2000 to 2020. https:// wWw.statista.com/statistics/603745/diesel-fuel-prices-netherlands/.

Statista, 2020b. Supermarkets with the highest market share for online grocery shopping in the Netherlands from 2015 to 2020. https://www.statista.com/statistics/659373/leading-onlinesupermarkets-based-on-share-of-shoppers-in-the-netherlands/.

Statista, 2020c. Total number of households in the Netherlands in 2020, by type. https:// WwW.statista.com/statistics/519863/total-number-of-households-in-the-netherlands/.

Statista, 2021. Online grocery shopping in the Netherlands - Statistics \& Facts. https://www.statista.com/ topics/6479/online-grocery-shopping-in-the-netherlands/.

Statistics Korea, 2016. Population Census. http://kostat.go.kr/portal/eng/pressReleases/8/7/ index.board?bmode=read\&aSeq=356507\&pageNo=\&rowNum=10\&amSeq=\&sTarget=\&sTxt=.

Strauss, A., Gülpınar, N., Zheng, Y., 2020. Dynamic pricing of flexible time slots for attended home delivery. European Journal of Operational Research .

This is Money, 2021. Online supermarket shopping has skyrocketed as Britons in lockdown buy their food from home like never before - But will this last and can it be profitable? https://www.thisismoney.co.uk/money/markets/article-9173751/Online-groceryshopping-took-year-profitable.html.

Vazquez-Noguerol, M., González-Boubeta, I., Portela-Caramés, I., Prado-Prado, J.C., 2021. Rethinking picking processes in e-grocery: A study in the multichannel context. Business Process Management Journal .

Vinsensius, A., Wang, Y., Chew, E.P., Lee, L.H., 2020. Dynamic incentive mechanism for delivery slot management in e-commerce attended home delivery. Transportation Science 54, 567-587.

Yang, X., Strauss, A.K., Currie, C.S., Eglese, R., 2016. Choice-based demand management and vehicle routing in e-fulfillment. Transportation science 50, 473-488.

Yang, X., Sun, Z., Ban, X.J., Holguín-Veras, J., 2014. Urban freight delivery stop identification with gps data. Transportation Research Record 2411, 55-61.

Yrjo, H., et al., 2001. Physical distribution considerations for electronic grocery shopping. International Journal of Physical Distribution \& Logistics Management . 


\section{Appendix}

\section{Appendix A}

A function $f(x)$ defined on the domain $x \in \Omega$ has a unique maximal solution if $f$ is strictly concave

on $\Omega$. Furthermore, $f$ is strictly concave if and only if $\frac{d^{2} f}{d x^{2}}<0$. So once we show $\frac{d^{2} \Pi_{e}}{d p^{2}}<0$, it will be sufficient to prove that there exists a unique optimal delivery fee $p^{*}$ that maximizes the e-grocery channel's contribution margin under the online strategy. Formally, we have

$$
\begin{aligned}
\frac{d^{2} \Pi_{e}}{d p^{2}}= & \left(m_{e}+p-f^{v}-c^{p}-c^{s}-\frac{\phi_{k} c^{t}}{2 \sqrt{\delta^{h} w \gamma_{e}}}\right) \frac{d^{2} \gamma_{e}}{d p^{2}} \\
& +\left(2-\tau^{p} \frac{\phi_{k} c^{t}}{2 \sqrt{\delta^{h} w}} \frac{u_{s}+u_{o}}{\left(u_{e}+u_{s}+u_{o}\right)^{2}}\right) \frac{d \gamma_{e}}{d p}
\end{aligned}
$$

Recall that the cost per order for the e-grocery channel is given by $\bar{C}_{e}=f^{v}+c^{p}+c^{s}-$ $\phi_{k} c^{t} / \sqrt{\delta^{h} w \gamma_{e}}$. Hence the e-grocery channel has a positive contribution margin only when $m_{e}+p-$ $f^{v}-c^{p}-c^{s}-\phi_{k} c^{t} / \sqrt{\delta^{h} w \gamma_{e}}>0$. Also, $\frac{d^{2} \gamma_{e}}{d p^{2}}=-\left(\tau^{p}\right)^{2} \frac{2\left(u_{s}+u_{o}\right)}{\left(u_{e}+u_{s}+u_{o}\right)^{3}}<0$ because $u_{s}+u_{o}>0$.

For the second term in (7), we have $\frac{d \gamma_{e}}{d p}=-\tau^{p} \frac{u_{s}+u_{o}}{\left(u_{e}+u_{s}+u_{o}\right)^{2}}<0$. In our model, $\delta^{h}$ is the household density. An average urban city has household density greater than $1,000 / \mathrm{km}^{2}$, for which $2-\tau^{p} \frac{\phi_{k} c^{t}}{2 \sqrt{\delta^{h} w}} \frac{u_{s}+u_{o}}{\left(u_{e}+u_{s}+u_{o}\right)^{2}}>0$. Combining all these expressions, we obtain $\frac{d^{2} \Pi_{e}}{d p^{2}}<0$.

We can similarly establish the inequality $\frac{d^{2} \Pi_{s}}{d p^{2}}<0$, which implies that $\frac{d^{2} \Pi}{d p^{2}}<0$. Hence there also exists a unique optimal delivery fee that maximizes the contribution margin in the omni-channel strategy. Note that the optimal delivery fee need not be same for the online strategy as for the omni-channel strategy.

\section{Appendix B}

Let $\Pi^{1}$ be the total contributions of the e-grocery channel $\left(\Pi_{e}^{1}\right)$ and the store channel $\left(\Pi_{s}^{1}\right)$ for the online strategy (i.e., $\Pi^{1}=\Pi_{e}^{1}+\Pi_{s}^{1}$ ), and let $p^{1}$ denote the corresponding optimal delivery fee. Let $\Pi^{2}$ analogously be the total contribution in the omni-channel strategy and $p^{2}$ the corresponding optimal delivery fee. Proposition 1 shows that the optimal fees are unique. Since the omni-channel strategy maximizes $\Pi^{2}$, it follows that $\Pi^{1} \leq \Pi^{2}$. By definition, $\Pi_{e}^{2} \leq \Pi_{e}^{1}$ because the online strategy maximizes $\Pi_{e}$. Therefore, $\Pi_{s}^{1}<\Pi_{s}^{2}$. The implication is that, for a marginal contribution $m$ per order in both channels, the store channel's market share is higher in the omni-channel strategy: $\gamma_{s}^{2}>\gamma_{s}^{1}$.

We know that $\gamma_{s}$ is increasing with the delivery fee $p$ - that is, since $\frac{d \gamma_{s}}{d p}>0$. If $p^{1}$ and $p^{2}$ are the optimal delivery fees for (respectively) the online and omni-channel strategies then, for $\gamma_{s}^{2}>\gamma_{s}^{1}$, we have $p^{1}>p^{2}$. According to equation (1), the market share of the e-grocery channel decreases with a higher delivery fee. So for $p^{1}>p^{2}$, the e-grocery channel has a lower market share in the omni-channel strategy than in the online strategy. 


\section{Appendix C}

Setting $\Pi_{e}=0$ yields

$$
p^{b}=f^{v}+c^{p}+c^{s}-m_{e}+\frac{c^{t} \phi_{k}}{\sqrt{\delta^{h} w}} \frac{1}{\sqrt{\gamma_{e}}}
$$

Parts (i) and (ii) of the proposition are proved as follows. It is clear from (8) that, if $\gamma_{e}>0$, then $p$ decreases with household density $\delta^{h}$ and increases with the picking cost $c^{p}$.

It is intuitive that high household density and automated picking reduce the total cost of serving a customer. Hence, the break-even delivery fee decreases in both cases.

(iii) The e-grocery channel's utility $u_{e}$ is independent of store density $\delta_{s}^{s}$. However, if $\delta_{s}^{s}$ increases then so does the store channel's utility. Since $\frac{d \gamma_{e}}{d u_{s}}<0$, it follows that the e-grocery channel's market share decreases with the utility of the store channel and thereby also with the store density. By (8), the break-even delivery fee decreases with the e-grocery channel's market share and therefore increases with store channel's store density. 